\title{
Catalyzed Hydrolysis of Waste MC nylon Using Zeolites in Subcritical Water
}

\author{
Wei Wang ${ }^{1}$, Linghui Meng ${ }^{1, *}$, Kunyue Leng ${ }^{1}$ and Yudong Huang ${ }^{1}$ \\ ${ }^{1}$ School of Chemical Engineering and Technology, Harbin Institute of Technology, Harbin 150001, PR China.
}

\begin{abstract}
In contrast with the conventional physical methods, the sub- and supercritical hydrolysis is not only a more environmentally friendly method to recycle the monomer casting nylon (MC nylon) wastes, but also a more feasible way to produce the corresponding monomer. In subcritical water, MC nylon was decomposed completely into water-soluble oligomers. The catalyzed hydrolysis of waste MC nylon using a series of $\mathrm{H}$-form zeolites in subcritical water is presented in this work. Among them, H-Beta especially showed an excellent catalytic property and remarkably high yield of the monomer $\varepsilon$-caprolactam.
\end{abstract}

\section{Introduction}

As a special kind of nylon 6, the monomer casting nylon (MC nylon) is synthetized by casting method through the anionic ring-opening polymerization of $\varepsilon$-caprolactam (CPL). Plenty of unique performances such as high strength, insulation, anticorrosive capacity, and oilresistance etc., make $\mathrm{MC}$ nylon having a wide range of applications as an engineering plastic [1,2]. However, the conventional physical recycling methods are not suitable for recycling $\mathrm{MC}$ nylon in some degree, because the molecular mass of MC nylon is up to $0.5-1.0 \times 10^{5} \mathrm{~g} / \mathrm{mol}$ which leads to an entanglement between the molecules in the melting state and a particularly high melt viscosity [3]. Catalytic hydrolysis or supercritical hydrolysis of MC nylon is much more environment-friendly, and the monomer could be easily extracted from water after the hydrolytic reaction [4-6], which has a relatively high price. As a solvent and reaction medium, sub- and supercritical water has been found an increasingly wide utilization in the fields of catalysis, degradation, extraction and separation etc. [7].

Traditionally, the hydrolysis is catalyzed by homogeneous acids which would bring the separation/recycling difficulties, expensive catalyst recovery and corrosion problems. Efficient catalysis over solid catalysts in hydrothermal condition can avoid all these problems, and the separation of catalyst is simple [8-10]. In this work, the H-form zeolites were used to catalyse the hydrolysis of MC nylon in subcritical water, and we found that the H-Beta zeolite, exhibiting high activity as well as good recyclability, could accelerate the reaction obviously and improve the yield of valuable monomer and is well suited for the hydrolysis of $\mathrm{MC}$ nylon.

\section{Experimental}

\subsection{Materials}

The ivory MC nylon sample for this study was unmodified and collected as processing wastes. Before hydrolysis, the sample was crushed into small pieces, then cleaned by deionized water and preserved in a desiccator. The water used in experiments was distilled water. Chromatographically pure $\varepsilon$-caprolactam and $\varepsilon$ aminocaproic acid were obtained from J \& K (Beijing, China).

The commercially available $\mathrm{H}$-form zeolites used in this work were provided by Nankai University Catalyst Co. (China) without binder material contents. The zeolites were calcined at $600{ }^{\circ} \mathrm{C}$ in air for $3 \mathrm{~h}$ prior to use.

\subsection{Hydrolysis in subcritical water}

The hydrolysis of MC nylon was performed in a $90 \mathrm{~cm}^{3}$ custom-made batch high pressure vessel, which was made of stainless steel and equipped with a pressure gauge as shown in Fig.1. The system was heated by an electric heating salt bath furnace with the mix of 0.45:0.55 (wt. /wt.) $\mathrm{NaNO}_{2}$ and $\mathrm{KNO}_{3}$.

After the addition of $1.0 \mathrm{~g} \mathrm{MC}$ nylon sample and desired amount of catalyst in water (mass ratio of liquid /solid was 30:1), the autoclave was sealed and subsequently placed in the salt bath. After the specified time at desired conditions, the autoclave was carried into an ice water bath quickly and cooled to room temperature. The pressure in the reactor dropped to ambient pressure in about $15 \mathrm{~s}$. After filtering and washing, the solid product, which was a mixture of residual MC nylon and solid catalyst, was dried at $80{ }^{\circ} \mathrm{C}$ for 6 hours. The liquid product was diluted and then filtered with $0.45 \mu \mathrm{m}$ filter membrane for further analysis.

The degradation rate of MC nylon hydrolysis $\left(D_{r}\right)$ and the yield of relevant monomer $\varepsilon$-caprolactam $\left(Y_{C P L}\right)$ could be defined as:

$$
\begin{gathered}
D_{r}(\%)=\frac{m_{0, \text { nylon }}-m_{t, \text { nylon }}}{m_{0, \text { nylon }}} \times 100 \\
Y_{C P L}(\%)=\frac{m_{t, C P L}}{m_{0, \text { nylon }}} \times 100
\end{gathered}
$$

Where $m_{t, C P L}$ referred to the measured mass of CPL at time t.

\subsection{Analyses and characterization}

The obtained solid products were examined by Fourier transform infrared spectroscopy (NICOLET-Nexus 670, USA). The mass ratio of dried $\mathrm{KBr}$ and dried solid 
sample was about 100: 1.0-1.5. The mixture powder was ground and compressed into a disk under the infrared lamp. The FTIR spectra were acquired in the wave number range of $400-4000 \mathrm{~cm}^{-1}$ with the optical resolution of $2 \mathrm{~cm}^{-1}$. Each sample was prepared and tested with 3 repetitions.

Liquid chromatography mass spectrometry (LC-MS) and high performance liquid chromatography (HPLC) with gradient elution method were used to qualitatively and quantitatively analyse the liquid phase products. The LC-MS instrument was Hybrid Finnigan LCQ DECA XP MAX system with chromatographic column ASB-C18 (5 $\mu \mathrm{m}, 150 \mathrm{~mm} \times 4.6 \mathrm{~mm})$. The HPLC apparatus was Agilent 1100 system with chromatographic column Zorbax SBC-18 (5 $\mu \mathrm{m}, 150 \mathrm{~mm} \times 4.6 \mathrm{~mm})$; UV detector read at $215 \mathrm{~nm}$; the temperature of column was $30{ }^{\circ} \mathrm{C}$. The mobile phase was the mixture of $0.1 \%$ acetic acid: acetonitrile $=90: 10$; velocity flow was $1.0 \mathrm{~mL} / \mathrm{min}$; injection volume was $5 \mu \mathrm{L}$.

Nitrogen sorption isotherm of the solid catalyst was obtained at $77 \mathrm{~K}$ on a 3H-2000PSI gas sorption and porosimetry system. The zeolite was normally prepared for measurement after degassing at $423 \mathrm{~K}$ under vacuum until a final pressure of $1 \times 10^{-3}$ Torr was reached.

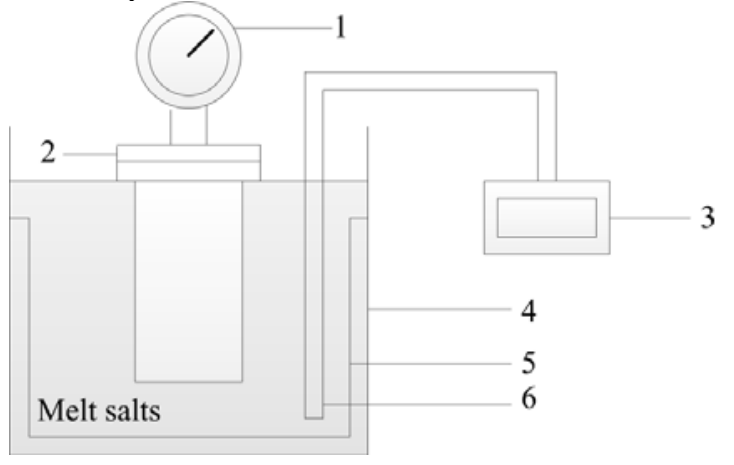

Figure 1 Apparatus for the decomposition of MC nylon in subcritical water (1-pressure gauge; 2-autoclave; 3-thermometer; 4-salt bath furnace; 5-heater; 6-thermocouple).

\section{Results and discussion}

\subsection{Reliability of hydrolysis results}

In subcritical water, $\mathrm{MC}$ nylon decomposed completely into water-soluble oligomers without any gas phase product at $345{ }^{\circ} \mathrm{C}$ within $45 \mathrm{~min}$. The infrared spectra of unreacted MC nylon and the solid product obtained at 15 min of the degradation were investigated to study the chemical composition of solid hydrolytic product. The unreacted MC nylon gives a spectra Fig.2 (a) basically the same as typical nylon 6. Fig.2 (b) obviously indicated that the solid phase product was the incompletely decomposed MC nylon.

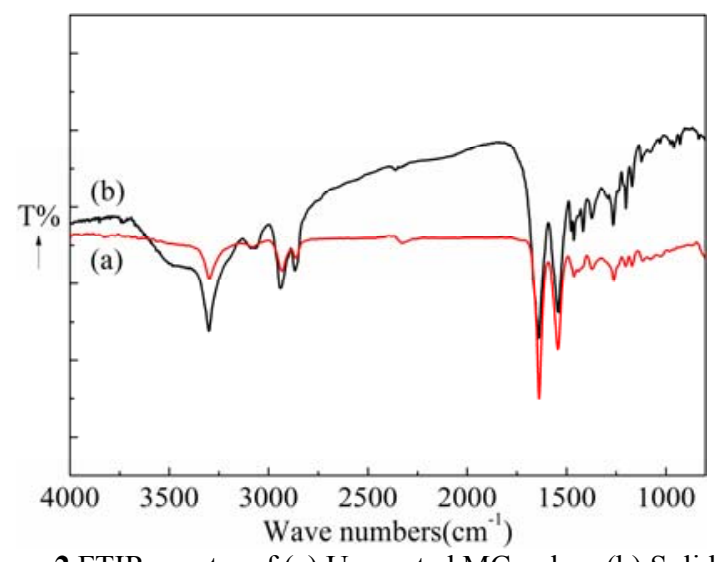

Figure 2 FTIR spectra of (a) Unreacted MC nylon, (b) Solid product existed at $15 \mathrm{~min}$ of the hydrolysis reaction $\left(345^{\circ} \mathrm{C}\right.$, added water $30 \mathrm{~g}$ ).

The liquid phase of the hydrolysis reaction was analysed by LC-MS, and the principal product was the target monomer $\varepsilon$-caprolactam (CPL) when the hydrolysis reaction was carried out to a certain extent. Fig. 3 shows the MS spectrum of the liquid phase products obtained at 90 min without the addition of solid catalyst. The peak at $\mathrm{m} / \mathrm{z} 114.20$ represents the monomer CPL, which is the most dominant composition.

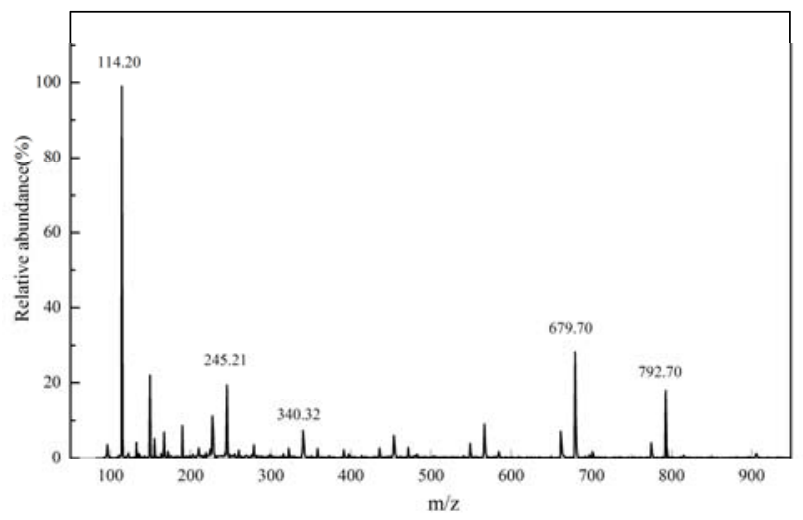

Figure 3 Mass spectrum of the liquid phase obtained at $345{ }^{\circ} \mathrm{C}$, $90 \mathrm{~min}$.

\subsection{The effect of the H-form zeolites}

Fig. 4 and Fig. 5 shows the degradation rate of MC nylon and the yield of CPL, which were two important factors to evaluation of the effect of hydrolysis, obtained by hydrolysis reactions using six different $\mathrm{H}$-form zeolites: H-Beta $(\mathrm{H} \beta)$ with $\mathrm{Si} / \mathrm{Al}$ ratios 25 and 40, HUSY and HZSM-5 with $\mathrm{Si} / \mathrm{Al}$ ratios 25,40 and 80 , respectively. The characterization data of the zeolite employed in this work are summarized in Table 1.

As it can be seen in Fig.4, the degradation rate for catalyzed hydrolysis was much higher than the noncatalyzed hydrolysis under the same reaction condition, especially the H-Beta zeolites. The value of the degradation rate was improved from less than $60 \%$ to almost $100 \%$ as using the $\mathrm{H} \beta-40$ while the increment as using the other types was less obvious. Meanwhile, the yield of CPL at $320{ }^{\circ} \mathrm{C}$ and 45 min was only $25 \%$ and increased to more than $55 \%$ due to the application of $\mathrm{H} \beta$ zeolites. Compared with the other $\mathrm{H}$-form zeolites, the $\mathrm{H}$ Beta zeolites have the largest external surface area, which 
was believed to be the essential factor for the MC nylon hydrolysis in subcritical water. The solid catalyst used in this work accelerated the rate of reaction obviously because it could induce the scission of amide groups.

Table 1 Properties of $\mathrm{H}$-form zeolites

\begin{tabular}{|c|c|c|c|}
\hline Sample & Si/Al ratio & $\mathrm{S}_{\mathrm{BET}} / \mathrm{m}^{2} \cdot \mathrm{g}^{-1}$ & $\begin{array}{c}\text { External } \\
\text { surface area/ } \\
\mathrm{m}^{2} \cdot \mathrm{g}^{-1}\end{array}$ \\
\hline $\mathrm{H} \beta-25$ & 25 & 513.69 & 133.31 \\
\hline $\mathrm{H} \beta-40$ & 40 & 507.32 & 97.16 \\
\hline HUSY & 25 & 736.10 & 100.10 \\
\hline HZSM-5(25) & 25 & 352.95 & 44.14 \\
\hline HZSM-5(40) & 40 & 363.43 & 38.28 \\
\hline HZSM-5(80) & 80 & 363.46 & 38.22 \\
\hline
\end{tabular}

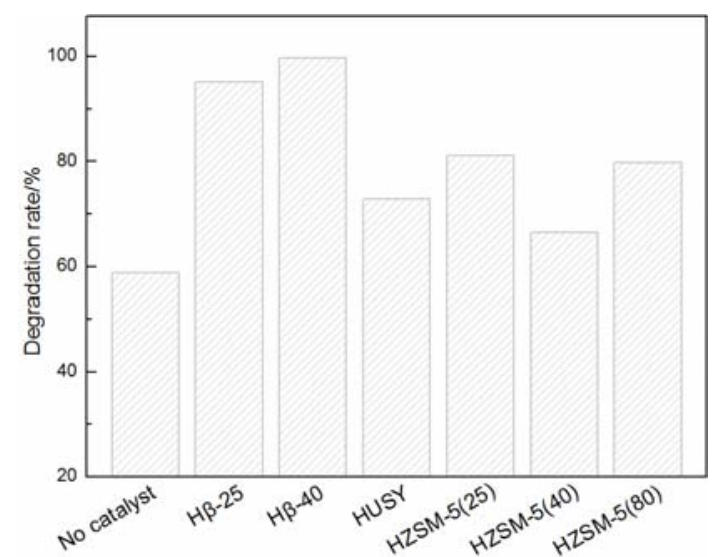

Figure 4 Degradation rate of MC nylon hydrolysis using different zeolites as catalysts; Reaction conditions: MC nylon $(1.0 \mathrm{~g})$; catalyst $(0.5 \mathrm{~g})$; water $(45 \mathrm{ml}) ; 320{ }^{\circ} \mathrm{C}, 45 \mathrm{~min}$.

\subsection{Recyclability of the solid catalyst}

The reusability of a solid catalyst is a very important parameter for its evaluation, so the catalyst recycling studies using the optimal $\mathrm{H}$-form zeolite, $\mathrm{H} \beta-25$, were carried out for the discussion of recyclability of this solid catalyst in subcritical water condition. Fig.6 and Fig.7 shows the degradation rate and yield of CPL as using the $\mathrm{H} \beta-25$ for three cycles, respectively. The degradation rate of waste $\mathrm{MC}$ nylon for the first recycling was about $95 \%$, and then remained stable at $100 \%$ in subsequent recycling experiments (Fig. 6). The yield of CPL in the recycling tests was maintaining in the range of $55-65 \%$ with a slightly decrease after the first recycle (Fig.7). The catalyst was still effective after four repeated experiments, so the catalytic performance of $\mathrm{H}$-form zeolites was relatively stable under the hydrothermal environment.

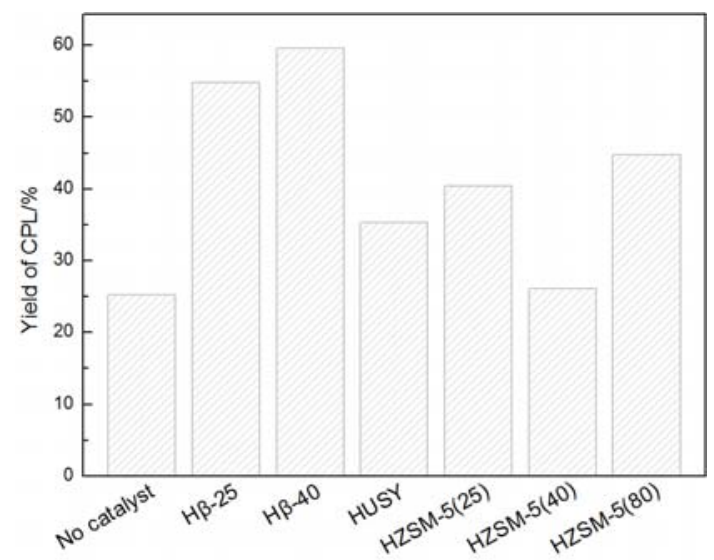

Figure 5 Yield of CPL using different zeolites as catalysts Reaction conditions: MC nylon (1.0 g); catalyst ( $0.5 \mathrm{~g})$; water (45 ml); $320{ }^{\circ} \mathrm{C}, 45 \mathrm{~min}$.

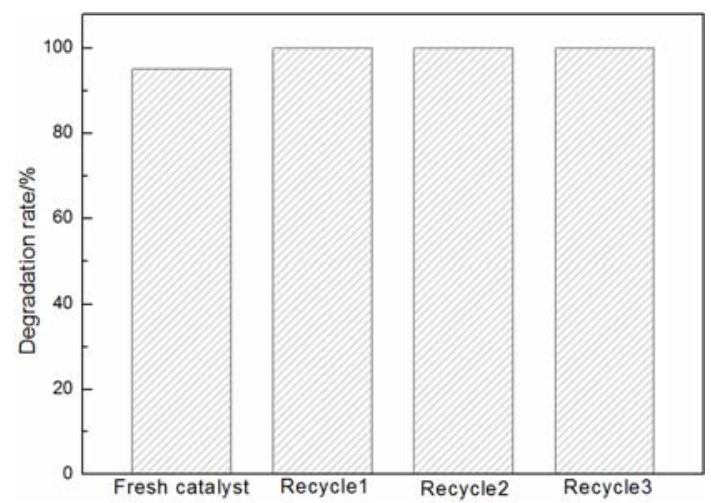

Figure 6 Degradation rate of MC nylon hydrolysis after the recycling test using $\mathrm{H} \beta-25$. Reaction conditions: $\mathrm{MC}$ nylon (1.0 g); catalyst $(0.5 \mathrm{~g})$; water $(45 \mathrm{ml}) ; 345{ }^{\circ} \mathrm{C}, 30 \mathrm{~min}$.

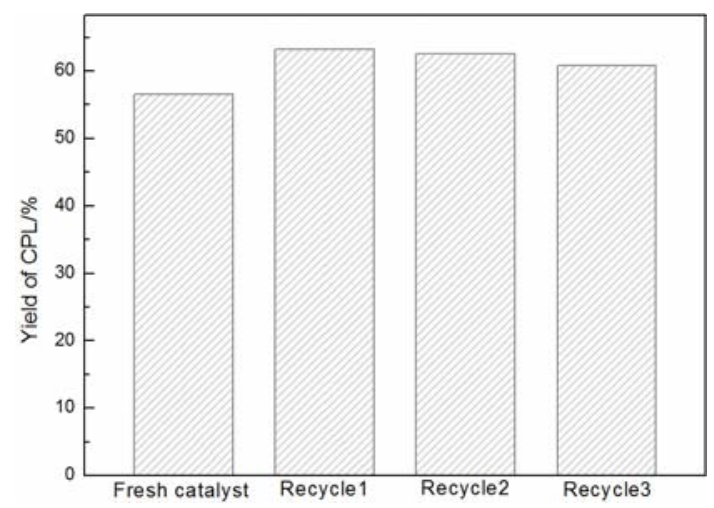

Figure 7 Yield of CPL after the recycling test using H $3-25$. Reaction conditions: MC nylon (1.0 g); catalyst ( $0.5 \mathrm{~g})$; water (45 ml);345 ${ }^{\circ} \mathrm{C}, 30 \mathrm{~min}$.

\section{Conclusions}

MC nylon was subjected to hydrolytic degradation using the subcritical water in this work. The solid phase product existed in the initial period of the decomposition was unreacted MC nylon and the main product in liquid phase was $\varepsilon$-caprolactam, which is the target monomer and makes the hydrolysis of waste MC nylon economically desirable. Solid acids are promising catalysts for hydrolysis of MC nylon due to they are easily separable and reusable, and thus avoid waste generation. In this 
work, we have presented that the H-form zeolites, especially the $\mathrm{H} \beta$ type, showed the relatively high yield of the monomer CPL from the waste MC nylon under hydrothermal conditions. This catalyzed hydrolysis using the zeolites catalyst with an excellent catalytic property and a high stability opens up new opportunities for the efficient use of the waste $\mathrm{MC}$ nylon resource as a chemical feedstock.

\section{References}

[1] Xu S, Zhao X, Ye L. PLYM-PLAST TECHNOL. 51, 7 (2012)

[2] $\mathrm{Su} \mathrm{K}-\mathrm{H}, \mathrm{Lin} \mathrm{J}-\mathrm{H}$, Lin C-C J MATER PROCESS TECH. 192 (2007)

[3] Wang W, Meng L, Huang Y. POLYM DEGRAD STABIL, 110(2014)

[4] Goto M, Sasaki M, Hirose T. J MATER SCI. 41, $5(2006)$

[5] Iwaya T, Sasaki M, Goto M. POLYM DEGRAD STABIL. 91,9(2006)

[6] Chen J, Liu G, Jin L, et al. J ANAL APPL PYROL. 47, 3(2009)

[7] Savage PE. J SUPERCRIT FLUID. 47, 3: 407-414 (2009)

[8] Kuo C-H, Poyraz AS, Jin L, et al. Green Chem. 16, 2(2014)

[9] Kobayashi H, Ito Y, Komanoya T, et al. Green Chem. 13, 2(2011)

[10]Wang J, Xu W, Ren J, et al. Green Chem. 13, 10(2011) 